Research Perspective

\title{
Improving therapy in metastatic uveal melanoma by understanding prior failures
}

\author{
Daniel J. Olson ${ }^{1}$ and Jason J. Luke ${ }^{2}$ \\ ${ }^{1}$ University of Chicago Comprehensive Cancer Center, Chicago, IL, USA \\ 2 UPMC Hillman Cancer Center, UPMC, Pittsburgh, PA, USA \\ Correspondence to: Jason J. Luke, email: Iukejj@upmc.edu \\ Keywords: uveal melanoma; cabozantinib; targeted therapy; immunotherapy \\ Received: April 06, $2020 \quad$ Accepted: April 14, $2020 \quad$ Published: June 1, 2020
}

Copyright: ( 2020 Olson and Luke. This is an open-access article distributed under the terms of the Creative Commons Attribution License 3.0 (CC BY 3.0), which permits unrestricted use, distribution, and reproduction in any medium, provided the original author and source are credited.

Metastatic uveal melanoma (UM) has historically been a particularly difficult sub-set of disease to treat in the metastatic setting. Multiple early phase clinical trials of chemo-, targeted and immunotherapies have consistently failed to demonstrate convincing efficacy signals, and overall survival outcomes remain poor [1]. Despite negative results, these studies do set benchmark clinical outcome standards [2] and answer important scientific questions within the field. This allows researchers to shift efforts towards potentially more promising strategies and therapies that may ultimately benefit patients. One issue that has potentially limited the field to date has been a reliance upon primary disease to design therapeutic approaches in the metastatic setting. Recently The Cancer Genome Atlas [3] has described the genomics of primary UM, however studies of metastatic disease are only starting to emerge [4-6]. While analyses of primary UM have been insightful in the prognostication of primary tumor features associated with higher risks of metastases and poor clinical outcomes [7], these efforts may not have been optimal toward elucidating the next generation of therapeutic targets in metastatic UM .

These concepts around drug development in UM were, in part, illustrated by the recently-published, "Randomized Phase II Trial and Tumor Mutational Spectrum Analysis from Cabozantinib versus Chemotherapy in Metastatic Uveal Melanoma (Alliance A091201)" [8]. The overexpression of the tyrosine kinase MET from primary UM biospecimens, which associated with a significantly higher risk of death from metastatic UM and could be blocked in UM cell lines [9], served as a rationale for the study. Within the clinical trial, MET was targeted by cabozantinib, a small molecule inhibitor of multiple tyrosine kinases, including VEGFR2 and MET. The trial randomized patients with metastatic UM 2:1 to cabozantinib versus standard of care chemotherapy with temozolomide or dacarbazine. The primary endpoint of the study was progression-free survival at four months (PFS4), where a null hypothesis PFS4 of $15 \%$ was tested against an alternate PFS4 of 40\%. Secondary endpoints included overall survival (OS), RECIST response rate, and safety. Ultimately, no differences in PFS4, PFS, or OS were observed and toxicity was found to be higher in the cabozantinib arm relative to chemotherapy. An exploratory analysis using whole exome sequencing of metastatic tumor specimens from trial patients was also completed. This revealed both well described (e.g. GNAQ, GNA11, BAP1, SF3B1), and lesser known mutations, and also revealed an average total tumor mutational burden (TMB) of 46 mutations/megabase (mut/Mb) across metastatic UM tumors. This was substantially lower than the what is commonly described for cutaneous melanoma (e.g. > $400 \mathrm{mut} / \mathrm{Mb}$ ), highlighting the unique mutational profile of UM.

The molecular profile of UM, largely defined through primary UM biospecimens, also has informed previous clinical trials targeting the RAS-ERK pathway, which remains constitutively activated in patients with GNAQ/GNA11 mutations. Within the RAS-ERK pathway, MEK inhibition demonstrated early activity with the introduction of selumetinib, an oral selective MEK1/2 inhibitor. In an open-label phase II study comparing selumetinib to temozolomide or dacarbazine, median PFS was improved in the selumetinib arm [10]. This prompted the larger phase III SUMIT study where selumetinib was combined with chemotherapy and compared to chemotherapy alone; however, selumetinib failed to meet its primary PFS endpoint: no significant difference was observed for selumetinib as compared to chemotherapy alone (PFS 2.8 vs. 1.8 months, $\mathrm{p}=0.32$ ) with minimal associated response rates $(3.1 \%$ vs. $0 \%)$ between selumetinib and chemotherapy [11]. Additionally, multiple phase I and phase II studies have failed to show substantial clinical benefit when targeting other molecular 
targets upstream, such as Protein Kinase C6, and downstream within the mitogen-activated protein kinase (MAPK) pathway [12-14]. Other molecular targets in UM have also been tested in clinical trials, but have similarly yielded very limited clinical activity; this includes VEGF (bevacizumab), c-KIT (imatinib, sunitinib) and epidermal growth factor inhibitors (gefitinib) [15-17].

The introduction of immunotherapy offers a different potential strategy for the treatment metastatic UM. Unlike cutaneous melanoma, immunotherapy in UM will likely rely on distinct modalities as initial outcomes with immune checkpoint inhibitors (ICIs) have been disappointing. To date, multiple case series and early phase trials have evaluated PD1 and CTLA4 antibodies for metastatic UM - alone or in combination - and have consistently demonstrated limited clinical benefit and low response rates [15-17]. For example, in a recent phase II trial, treatment with combined PD1 and CTLA4 antibodies generated a $17 \%$ response rate - one of the highest response rates reported across multiple early phase studies - while in cutaneous melanoma, response rates of $58 \%$ have been with the same regimen $[18,19]$. Some evidence suggests that checkpoint blockade approaches might be useful in the subset of patients with low volume or non-hepatic involved UM, though such patients are relatively rare [20]. Despite these outcomes with ICIs, some encouraging data is emerging that UM can be successfully targeted with alternate immunotherapy modalities. A recent phase II trial in metastatic UM where autologous tumor-infiltrating lymphocytes (TIL) and high-dose interleuikin-2 were infused after lympho-depleting chemotherapy demonstrated a 35\% (7/20) response rate [21]. Additionally, tebentafusp, a first-in-class immune-mobilizing monoclonal $\mathrm{T}$ cell receptor against cancer (ImmTAC), which is made up of a human leukocyte antigen-A*02:01 restricted soluble $\mathrm{T}$ cell receptor fused to an anti-CD3 single-chain variable fragment, has demonstrated early signs of activity in UM. Tabentafusp recruits CD3+ T cells to target cells that express the melanoma-associated antigen gp100, thus re-directing $\mathrm{T}$ cells towards melanoma cells. A phase 1 study of tebentafusp in UM showed one-year overall survival of $74 \%$, which is numerically superior to the oneyear overall survival published for historical treatment modalities in UM that have not surpassed 55\% [22]. While these efficacy signals are still in early phases of testing, they do suggest that UM may ultimately be amenable to targeting by immunotherapy. As the understanding of the likely unique immunobiology of UM improves, the hope remains that these promising therapies translate into improvements in clinical outcomes for patients with UM.

Finally, another note of optimism for the treatment of UM is the integration of multi-omic technologies in the development of potential drug targets. Such technologies generate large amounts of genomic, epigenomic and proteomic data from UM biospecimens, and along with bioinformatic pipelines, can greatly improve collective knowledge around UM oncogenesis [3,5,23]. This improved understanding of the oncogenesis of UM can potentially identify molecular weaknesses and potential drug targets possibly including the recently identified Hippo/YAP pathway as potentially a high priority target in UM [24]. This approach also applies to immunotherapy approaches in UM where an improved understanding of the unique immunobiology of UM may offer more potential drug targets and treatment strategies to improve clinical outcomes for patients with metastatic UM.

\section{CONFLICTS OF INTEREST}

DJO declares no disclosures or conflicts of interest. JJL declares Data and Safety Monitoring Board: TTC Oncology; Scientific Advisory Board: 7 Hills, Actym, Alphamab Oncology, Kanaph, Mavu (now part of AbbVie), Onc.AI, Pyxis, Springbank, Tempest; Consultancy: Abbvie, Akrevia, Algios, Array, Astellas, Bayer, Bristol-Myers Squibb, Eisai, EMD Serono, Ideaya, Incyte, Janssen, Merck, Mersana, Novartis, PTx, RefleXion, Regeneron, Silicon, Tesaro, Vividion; Research Support: (all to institution for clinical trials unless noted) AbbVie, Agios (IIT), Array (IIT), Astellas, Bristol-Myers Squibb, CheckMate (SRA), Compugen, Corvus, EMD Serono, Evelo (SRA), Five Prime, FLX Bio, Genentech, Immatics, Immunocore, Incyte, Leap, MedImmune, Macrogenics, Necktar, Novartis, Palleon (SRA), Merck, Springbank, Tesaro, Tizona, Xencor; Travel: Akrevia, Bayer, Bristol-Myers Squibb, EMD Serono, Incyte, Janssen, Merck, Mersana, Novartis, Pyxis, RefleXion; Patents: (both provisional) Serial \#15/612,657 (Cancer Immunotherapy), PCT/US18/36052 (Microbiome Biomarkers for Anti-PD-1/PD-L1 Responsiveness: Diagnostic, Prognostic and Therapeutic Uses Thereof)

\section{FUNDING}

JJL acknowledges Department of Defense Career Development Award (W81XWH-17-1-0265). DJO acknowledges Clinical Therapeutics Training Grant (T32GM007019).

\section{REFERENCES}

1. Luke JJ, Triozzi PL, McKenna KC, Van Meir EG, Gershenwald JE, Bastian BC, Gutkind JS, Bowcock AM, Streicher HZ, Patel PM, Sato T, Sossman JA, Sznol M, et al. Biology of advanced uveal melanoma and next steps for clinical therapeutics. Pigment Cell Melanoma Res. 2015; 28:135-47. https://doi.org/10.1111/pcmr.12304. PMID:25113308

2. Khoja L, Atenafu EG, Suciu S, Leyvraz S, Sato T, Marshall E, Keilholz U, Zimmer L, Patel SP, Piperno-Neumann S, Piulats J, Kivelä TT, Pfoehler C, et al. Meta-analysis in 
metastatic uveal melanoma to determine progression free and overall survival benchmarks: an international rare cancers initiative (IRCI) ocular melanoma study. Ann Oncol. 2019; 30:1370-80. https://doi.org/10.1093/annonc/ mdz176. PMID:31150059

3. Robertson AG, Shih J, Yau C, Gibb EA, Oba J, Mungall KL, Hess JM, Uzunangelov V, Walter V, Danilova L, Lichtenberg TM, Kucherlapati M, Kimes PK, et al, and TCGA Research Network. Integrative Analysis Identifies Four Molecular and Clinical Subsets in Uveal Melanoma. Cancer Cell. 2017; 32:204-220.e15. https://doi. org/10.1016/j.ccell.2017.07.003. PMID:28810145

4. Karlsson J, Nilsson LM, Forsberg EM, Mitra S, Alsén S, Shelke G, Sah VR, Stierner U, All-Eriksson C, Einarsdottir B, Jespersen H, Ny L, Lindnér P, et al. Molecular profiling of driver events and tumor-infiltrating lymphocytes in metastatic uveal melanoma. bioRxiv. 2019. https://doi. org/10.1101/742023.

5. Durante MA, Rodriguez DA, Kurtenbach S, Kuznetsov JN, Sanchez MI, Decatur CL, Snyder H, Feun LG, Livingstone AS, Harbour JW. Single-cell analysis reveals new evolutionary complexity in uveal melanoma. Nat Commun. 2020; 11:496-10. https://doi.org/10.1038/s41467-01914256-1. PMID:31980621

6. Piperno-Neumann S, Larkin J, Carvajal RD, Luke JJ, Schwartz GK, Hodi FS, Sablin MP, Shoushtari AN, Szpakowski S, Chowdhury NR, Brannon AR, Ramkumar $\mathrm{T}$, de Koning L, et al. Genomic Profiling of Metastatic Uveal Melanoma and Clinical Results of a Phase I Study of the Protein Kinase C Inhibitor AEB071. Mol Cancer Ther. 2020; 19:1031-39. https://doi.org/10.1158/1535-7163. MCT-19-0098. PMID:32029634

7. Harbour JW, Chen R. The DecisionDx-UM Gene Expression Profile Test Provides Risk Stratification and Individualized Patient Care in Uveal Melanoma. PLoS Curr. 2013; 5. https://doi.org/10.1371/currents.eogt. af8ba80fc776c8f1ce8f5dc485d4a618. PMID:23591547

8. Luke JJ, Olson DJ, Allred JB, Strand CA, Bao R, Zha Y, Carll T, Labadie BW, Bastos BR, Butler MO, Hogg D, Munster PN, Schwartz GK. Randomized Phase II Trial and Tumor Mutational Spectrum Analysis from Cabozantinib versus Chemotherapy in Metastatic Uveal Melanoma (Alliance A091201). Clin Cancer Res. 2020; 26:80411. https://doi.org/10.1158/1078-0432.CCR-19-1223. PMID:31558480

9. Wu X, Zhou J, Rogers AM, Jänne PA, Benedettini E, Loda M, Hodi FS. c-Met, epidermal growth factor receptor, and insulin-like growth factor-1 receptor are important for growth in uveal melanoma and independently contribute to migration and metastatic potential. Melanoma Res. 2012; 22:123-32. https://doi.org/10.1097/ CMR.0b013e3283507ffd. PMID:22343486

10. Carvajal RD, Sosman JA, Quevedo JF, Milhem MM,
Joshua AM, Kudchadkar RR, Linette GP, Gajewski TF, Lutzky J, Lawson DH, Lao CD, Flynn PJ, Albertini MR, et al. Effect of selumetinib vs chemotherapy on progressionfree survival in uveal melanoma: a randomized clinical trial. JAMA. 2014; 311:2397-405. https://doi.org/10.1001/ jama.2014.6096. PMID:24938562

11. Carvajal RD, Piperno-Neumann S, Kapiteijn E, Chapman PB, Frank S, Joshua AM, Piulats JM, Wolter P, Cocquyt V, Chmielowski B, Evans TR, Gastaud L, Linette G, et al. Selumetinib in Combination With Dacarbazine in Patients With Metastatic Uveal Melanoma: A Phase III, Multicenter, Randomized Trial (SUMIT). J Clin Oncol. 2018; 36:1232-39. https://doi.org/10.1200/JCO.2017.74.1090. PMID:29528792

12. Shah S, Luke JJ, Jacene HA, Chen T, Giobbie-Hurder A, Ibrahim N, Buchbinder EL, McDermott DF, Flaherty KT, Sullivan RJ, Lawrence DP, Ott PA, Hodi FS. Results from phase II trial of HSP90 inhibitor, STA-9090 (ganetespib), in metastatic uveal melanoma. Melanoma Res. 2018; 28:60510. $\quad$ https://doi.org/10.1097/CMR.0000000000000509. PMID:30211813

13. Moschos SJ, Sullivan RJ, Hwu WJ, Ramanathan RK, Adjei AA, Fong PC, Shapira-Frommer R, Tawbi HA, Rubino J, Rush TS 3rd, Zhang D, Miselis NR, Samatar AA, et al. Development of MK-8353, an orally administered ERK1/2 inhibitor, in patients with advanced solid tumors. JCI Insight. 2018; 3:184. https://doi.org/10.1172/jci. insight.92352. PMID:29467321

14. Sullivan RJ, Hollebecque A, Flaherty KT, Shapiro GI, Rodon Ahnert J, Millward MJ, Zhang W, Gao L, Sykes A, Willard MD, Yu D, Schade AE, Crowe K, et al. A Phase I Study of LY3009120, a Pan-RAF Inhibitor, in Patients with Advanced or Metastatic Cancer. Mol Cancer Ther. 2020; 19:460-67. https://doi.org/10.1158/1535-7163.MCT-190681. PMID:31645440

15. Guenterberg KD, Grignol VP, Relekar KV, Varker KA, Chen HX, Kendra KL, Olencki TE, Carson WE 3rd. A pilot study of bevacizumab and interferon- $\alpha 2 b$ in ocular melanoma. Am J Clin Oncol. 2011; 34:87-91. https://doi. org/10.1097/COC.0b013e3181d2ed67. PMID:20458209

16. Hofmann UB, Kauczok-Vetter CS, Houben R, Becker JC. Overexpression of the KIT/SCF in uveal melanoma does not translate into clinical efficacy of imatinib mesylate. Clin Cancer Res. 2009; 15:324-29. https://doi. org/10.1158/1078-0432.CCR-08-2243. PMID:19118061

17. Patel SP, Kim KB, Papadopoulos NE, Hwu WJ, Hwu P, Prieto VG, Bar-Eli M, Zigler M, Dobroff A, Bronstein Y, Bassett RL, Vardeleon AG, Bedikian AY. A phase II study of gefitinib in patients with metastatic melanoma. Melanoma Res. 2011; 21:357-63. https://doi.org/10.1097/ CMR.0b013e3283471073. PMID:21738104

18. Pelster M, Gruschkus SK, Bassett R, Gombos DS, Shephard M, Posada L, Glover M, Diab A, Hwu P, Patel 
SP. Phase II study of ipilimumab and nivolumab (ipi/ nivo) in metastatic uveal melanoma (UM). J Clin Oncol. 2019; 37:9522. https://doi.org/10.1200/JCO.2019.37.15 suppl.9522.

19. Larkin J, Chiarion-Sileni V, Gonzalez R, Grob JJ, Rutkowski P, Lao CD, Cowey CL, Schadendorf D, Wagstaff J, Dummer R, Ferrucci PF, Smylie M, Hogg D, et al. Five-Year Survival with Combined Nivolumab and Ipilimumab in Advanced Melanoma. N Engl J Med. 2019; 381:1535-46. https://doi.org/10.1056/NEJMoa1910836. PMID:31562797

20. Johnson DB, Bao R, Ancell KK, Daniels AB, Wallace D, Sosman JA, Luke JJ. Response to Anti-PD-1 in Uveal Melanoma Without High-Volume Liver Metastasis. J Natl Compr Canc Netw. 2019; 17:114-17. https://doi. org/10.6004/jncen.2018.7070. PMID:30787124

21. Chandran SS, Somerville RP, Yang JC, Sherry RM, Klebanoff CA, Goff SL, Wunderlich JR, Danforth DN, Zlott D, Paria BC, Sabesan AC, Srivastava AK, Xi L, et al. Treatment of metastatic uveal melanoma with adoptive transfer of tumour-infiltrating lymphocytes: a singlecentre, two-stage, single-arm, phase 2 study. Lancet Oncol. 2017; 18:792-802. https://doi.org/10.1016/S14702045(17)30251-6. PMID:28395880

22. Damato BE, Dukes J, Goodall H, Carvajal RD. Tebentafusp: T Cell Redirection for the Treatment of Metastatic Uveal Melanoma. Cancers (Basel). 2019; 11:971. https://doi. org/10.3390/cancers 11070971. PMID:31336704

23. Shain AH, Bagger MM, Yu R, Chang D, Liu S, Vemula S, Weier JF, Wadt K, Heegaard S, Bastian BC, Kiilgaard JF. The genetic evolution of metastatic uveal melanoma. Nat Genet. 2019; 51:1123-30. https://doi.org/10.1038/s41588019-0440-9. PMID:31253977

24. Feng X, Arang N, Rigiracciolo DC, Lee JS, Yeerna H, Wang Z, Lubrano S, Kishore A, Pachter JA, König GM, Maggiolini M, Kostenis E, Schlaepfer DD, et al. A Platform of Synthetic Lethal Gene Interaction Networks Reveals that the GNAQ Uveal Melanoma Oncogene Controls the Hippo Pathway through FAK. Cancer Cell. 2019; 35:457-472.e5. https://doi.org/10.1016/j.ccell.2019.01.009. PMID:30773340 